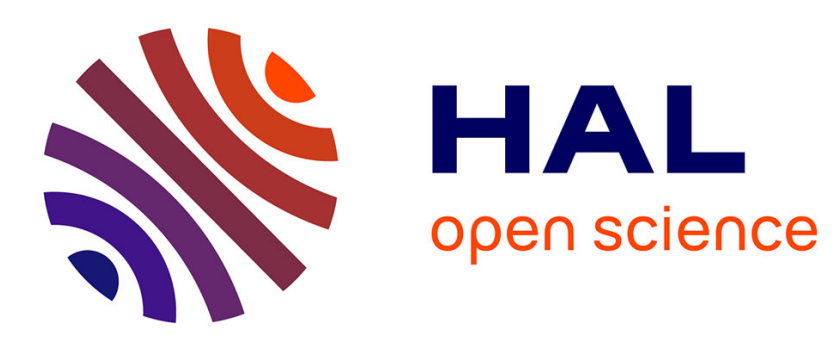

\title{
ANAEMIA IN CHRONIC RESPIRATORY FAILURE
}

Florian Kollert, Carolin Müller, Andrea Tippelt, Rudolf Jorres, Dominic

Heidinger, Corina Probst, Michael Pfeifer, Stephan Budweiser

\section{To cite this version:}

Florian Kollert, Carolin Müller, Andrea Tippelt, Rudolf Jorres, Dominic Heidinger, et al.. ANAEMIA IN CHRONIC RESPIRATORY FAILURE. International Journal of Clinical Practice, 2011, 65 (4), pp.479. 10.1111/j.1742-1241.2011.02631.x . hal-00623801

\section{HAL Id: hal-00623801 https://hal.science/hal-00623801}

Submitted on 15 Sep 2011

HAL is a multi-disciplinary open access archive for the deposit and dissemination of scientific research documents, whether they are published or not. The documents may come from teaching and research institutions in France or abroad, or from public or private research centers.
L'archive ouverte pluridisciplinaire HAL, est destinée au dépôt et à la diffusion de documents scientifiques de niveau recherche, publiés ou non, émanant des établissements d'enseignement et de recherche français ou étrangers, des laboratoires publics ou privés. 


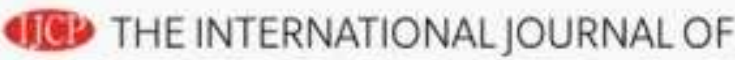 CLINICAL PRACTICE}

\section{ANAEMIA IN CHRONIC RESPIRATORY FAILURE}

\begin{tabular}{|c|c|}
\hline Journal: & International Journal of Clinical Practice \\
\hline Manuscript ID: & IJCP-11-10-0610.R1 \\
\hline Wiley - Manuscript type: & Original Paper \\
\hline $\begin{array}{r}\text { Date Submitted by the } \\
\text { Author: }\end{array}$ & 07-Dec-2010 \\
\hline Complete List of Authors: & $\begin{array}{l}\text { Kollert, Florian; University Medical Center Freiburg, Rheumatology } \\
\text { and Clinical Immunology } \\
\text { Müller, Carolin; Donaustauf Hospital, Center for Pneumology } \\
\text { Tippelt, Andrea; Donaustauf Hospital, Center for Pneumology } \\
\text { Jorres, Rudolf; Ludwig-Maximilians-University Munich, Institute and } \\
\text { Outpatient Clinic for Occupational and Environmental Medicine } \\
\text { Heidinger, Dominic; Donaustauf Hospital, Center for Pneumology } \\
\text { Probst, Corina; University Medical Center Freiburg, Department of } \\
\text { Pneumology } \\
\text { Pfeifer, Michael; University of Regensburg, Department of Internal } \\
\text { Medicine II, Division of Respirology, University of Regensburg, } \\
\text { Regensburg, Germany; Donaustauf Hospital, Center for } \\
\text { Pneumology } \\
\text { Budweiser, Stephan; RoMed Clinic, Department of Internal Medicine } \\
\text { III, Division of Respirology; Donaustauf Hospital, Center for } \\
\text { Pneumology }\end{array}$ \\
\hline Specialty area: & \\
\hline
\end{tabular}

\section{SCHOLARONE Manuscripts}




\section{ANAEMIA IN CHRONIC RESPIRATORY FAILURE}

Florian Kollert $^{1,2}$, MD; Carolin Müller ${ }^{1}$; Andrea Tippelt ${ }^{1}$; Rudolf A. Jörres ${ }^{3}, \mathrm{PhD}$; Dominic Heidinger ${ }^{1}$, MD; Corina Probst, MD ${ }^{6}, \mathrm{MD}$; Michael Pfeifer ${ }^{1,4}$, MD and Stephan Budweiser ${ }^{1,5}$, MD

${ }^{1}$ Centre for Pneumology, Donaustauf Hospital, Donaustauf, Germany

${ }^{2}$ Department of Rheumatology and Clinical Immunology, University Medical Centre, Freiburg, Germany

${ }^{3}$ Institute and Outpatient Clinic for Occupational, Social and Environmental Medicine, Ludwig-Maximilians-University, Munich, Germany

${ }^{4}$ Department of Internal Medicine II, Division of Respirology, University of Regensburg, Regensburg, Germany

${ }^{5}$ Department of Internal Medicine III, Division of Respirology, RoMed Clinic, Rosenheim, Germany

${ }^{6}$ Department of Pneumology, University Medical Centre, Freiburg, Germany

Running title: Anaemia in chronic respiratory failure

\section{Address for correspondence:}

Dr. Florian Kollert, MD

Department of Rheumatology and Clinical Immunology

University Medical Centre Freiburg

Hugstetterstr. 55

79106 Freiburg im Breisgau

Germany

Email: florian.kollert@uniklinik-freiburg.de

Phone: +49-(0)761/2703544 FAX: +49-(0)761/2703531

Disclosures: F.K., C.M., R.A.J., D.H., C.P., M.P. and S.B. have no conflicts of interest. 


\begin{abstract}
Background: In patients with severe chronic obstructive pulmonary disease (COPD), anaemia is common and associated with impaired long-term survival and quality of life. Whether anaemia is also prevalent in patients with other severe, non-inflammatory respiratory diseases has not yet been systematically tested.

Methods: In 595 patients with obstructive (OD, 54.8\%) or restrictive disease (RD, 45.2\%) and chronic respiratory failure $(\mathrm{CRF})$, anthropometric data, laboratory parameters, lung function, blood gases and co-morbidities were assessed prior to initiation of home mechanical ventilation. Patients were classified as anaemic based on haemoglobin $(\mathrm{Hb})$ levels $(\mathrm{Hb}$ $<12 / 13 \mathrm{~g} / \mathrm{dl}$, female/male). Patients with known causes for anaemia were excluded.

Results: In patients with CRF the prevalence of anaemia was $13.3 \%$ and not different between RD $(11.5 \%)$ and OD (14.7\%) $(\mathrm{p}=0.276)$. A sex-related difference occurred only in OD (7.9\% (f) versus $17.3 \%(\mathrm{~m}) ; \mathrm{p}=0.035)$. Patients with $\mathrm{OD}$ and anaemia presented with higher age $(\mathrm{p}=0.003), \mathrm{pH}(\mathrm{p}=0.014)$ and arterial oxygen pressure $\left(\mathrm{PaO}_{2}\right)(\mathrm{p}=0.012)$, lower body-mass index $(B M I)(p=0.011)$ and total protein $(p=0.012)$, and higher rates of coronary heart disease $(\mathrm{p}=0.01)$, cardiac arrhythmia $(\mathrm{p}=0.014)$ and diabetes mellitus $(\mathrm{p}=0.003)$ in comparison to nonanaemic patients. In patients with $\mathrm{RD}$ anaemia was associated with higher age, $(\mathrm{p}=0.008), \mathrm{pH}$ $(\mathrm{p}=0.011)$ and lower leucocytes numbers $(\mathrm{p}=0.006)$.

Conclusions: Anaemia is frequent not only in COPD but also in other severe respiratory diseases combined with CRF. It was associated with advanced age, several co-morbidities, impaired nutritional state and elevations of $\mathrm{pH}$ and $\mathrm{PaO}_{2}$, probably due to hyperventilation. Its prognostic impact has to be elucidated in future studies.
\end{abstract}

Word count of abstract: 248

Key words: Respiratory failure; anaemia; prognostic factors; COPD; restrictive disease. 


\section{What is already known about this topic?}

Anaemia is highly prevalent in COPD and associated with increased long-term mortality. In contrast, the prevalence of anaemia has not yet been tested in other severe, non-inflammatory respiratory diseases.

\section{What does this article add?}

The prevalence of anaemia was high in COPD but also in other severe respiratory diseases, even after exclusion of relevant co-morbidities. These findings suggest that anaemia is a common phenomenon in patients with severe chronic respiratory disease, which has a multifactorial origin and is not only explained by systemic inflammation. 


\section{INTRODUCTION}

Anaemia of chronic disease (ACD) is one of the most frequent forms of anaemia which is often observed in patients with infections, cancer and chronic inflammatory or autoimmune diseases. The underlying mechanisms are complex, including dysregulation in iron homeostasis and erythropoietin production, impaired proliferation of erythroid progenitor cells and reduced life span of red blood cells. Moreover, ACD often is superimposed by malnutrition, bleeding, renal failure and effects of medication or interventions (1). In patients with chronic renal failure, congestive heart failure, or malignant diseases, anaemia has been shown to be associated with impaired quality of life and prognosis (2-4).

A retrospective analysis of patients with chronic obstructive pulmonary disease (COPD) receiving long-term oxygen therapy (LTOT) has revealed that anaemia is also common in severe COPD, being linked to morbidity and survival (5). Moreover, a prospective study of stable COPD patients with a wide range of airflow limitation reported haemoglobin levels of $<13 \mathrm{~g} / \mathrm{dl}$ in $17 \%$ of patients, whereby anaemia acted as a risk factor for dyspnoea, functional capacity and mortality (6). However, a limitation of these investigations appeared to be that co-morbidities relevant for anaemia were not excluded. Thus COPD is associated with many co-morbidities (7), not only renal failure (8), which could substantially contribute to anaemia. In addition, the clinical significance and pathogenesis of anaemia in COPD are still under discussion. Erythropoietin resistance secondary to systemic inflammation has been proposed as a contributor (9), but a number of other mechanisms, such as malnutrition or oxidative stress, may also play a role in severe forms of the disease (10), as well as medication, such as theophylline (11).

Based on these considerations we aimed to assess the prevalence of anaemia in a large group of patients with severe respiratory diseases of different aetiologies, to compare this with the prevalence found in COPD and to identify risk factors linked to anaemia. All patients were of comparable clinical state with regard to the fact that they received home mechanical 
ventilation (HMV) due to chronic respiratory failure (CRF). To reduce the bias by confounders, patients with known causes for anaemia were strictly excluded from the analysis. 


\section{METHODS}

\section{Study population}

Patients who were discharged with HMV due to CRF from the Donaustauf Hospital, Centre for Pneumology, University of Regensburg, between April 1992 and March 2007 were identified from a data base. Since January 2002 data entry was performed prospectively. The underlying disorders were classified as obstructive disorders (OD) (COPD or overlap syndrome) or restrictive disorders (RD) including obesity-hypoventilation syndrome (OHS), thoracic restrictive diseases (TRD), neuromuscular disorders (NMD), and mixed respiratory disease (predominately interstitial lung diseases). The diagnosis of COPD was based on clinical history, symptoms, a ratio of forced expiratory volume in one second $\left(\mathrm{FEV}_{1}\right)$ to inspiratory vital capacity (VC) of $<70 \%$, and $\mathrm{FEV}_{1}$ being $<50 \%$ predicted. In case of $\mathrm{FEV}_{1}$ $>50 \%$ (and $\mathrm{FEV}_{1} / \mathrm{VC}<70 \%$ ) and in the presence of chronic hypercapnia, patients were classified as "overlap syndrome" (OL) (12). OHS was defined as obesity (BMI $>30 \mathrm{~kg} / \mathrm{m}^{2}$ ) plus daytime hypercapnia $\left(\mathrm{PaCO}_{2} \geq 45 \mathrm{~mm} \mathrm{Hg}\right)$ and symptoms of hypoventilation (13).

\section{Selection criteria}

Only patients with complete blood count data prior to initiation of HMV were included. Based on the fact that intensive care or endotracheal intubation is associated with repeated blood withdrawal or blood loss due to interventions, we also excluded all patients who had undergone invasive ventilation before initiation of HMV. It has been shown, that the prevalence of renal anaemia in patients with an estimated glomerular filtration rate (eGFR) between 30 and $60 \mathrm{ml} / \mathrm{min} / 1.73 \mathrm{~m}^{2}$ is low (14), thus only patients with eGFR $<30 \mathrm{ml} / \mathrm{min} / 1.73$ $\mathrm{m}^{2}$ were excluded. Further exclusion criteria were known malignancies/haematological disorders within the last 5 years, surgeries, interventions, accidents or haemorrhage within the last 3 months; additional chronic inflammatory, infectious or autoimmune diseases; previous 
gastrointestinal resection that could evoke malabsorption; substitution of iron, folate or vitamin $\mathrm{B}_{12}$; preceding withdrawal of blood due to polyglobulia or blood transfusion.

\section{Measurements}

All data were assessed at the beginning of the hospital stay. Routine blood parameters including haemoglobin $(\mathrm{Hb})$, haematocrit $(\mathrm{Hk})$, leukocyte number, C-reactive protein (CRP), creatinine and total protein (if available) were documented upon admission. Patients were classified as anaemic $(\mathrm{Hb}<12 \mathrm{~g} / \mathrm{dl}$ in females, $\mathrm{Hb}<13 \mathrm{~g} / \mathrm{dl}$ in males) (15) or normal. BMI was calculated as weight $(\mathrm{kg}) /$ height $(\mathrm{m})^{2}$. Glomerular filtration rate was estimated by the "Modification of Diet in Renal Disease (MDRD)" study equation, as this formula is known to be more accurate especially in older and obese patients than the Cockroft-Gault equation (16).

Chronic renal failure was defined by an eGFR $<60 \mathrm{ml} / \mathrm{min} / 1.73 \mathrm{~m}^{2}$. Daytime capillary blood gas values $\left(\mathrm{pH}\right.$, arterial oxygen pressure $\left(\mathrm{PaO}_{2}\right)$, arterial carbon dioxide pressure $\left(\mathrm{PaCO}_{2}\right)$, base excess $\left.(\mathrm{BE})\right)$ were determined prior to HMV therapy from the hyperaemic earlobe. Only values acquired without additional oxygen supplementation were used. Spirometry and bodyplethysmography were performed according to guidelines of the American Thoracic Society (ATS) / European Respiratory Society (ERS) (17) using ERS reference values (18). Co-morbidities, such as coronary heart disease, left heart failure, cardiac arrhythmias, arterial hypertension and diabetes mellitus, as well as concomitant medication, such as inhaled bronchodilators, theophylline or anti-hypertensive medication, were documented. The presence of acute infection, such as pneumonia or lower urinary tract infection, was derived from clinical findings and/or CRP levels $>20 \mathrm{mg} / \mathrm{dl}$.

\section{Statistical analysis}

The results are shown as median and quartiles. For the comparison of groups, the MannWhitney U-test or t-test was used in case of continuous variables, and Fisher's exact test for categorical variables. Parameters which were significant different between anaemic and non- 
anaemic patients, and disease category (OD versus $\mathrm{RD}$ ) as binary variable, were evaluated by multivariate regression analyses to identify independent factors. A p-value $<0.05$ was considered statistically significant. Calculations were performed using PASW statistics 17.0 (Chicago, IL, USA). 


\section{RESULTS}

\section{Study population}

Within the study period 966 patients were discharged with HMV. In total, 939 patients showed appropriate laboratory data prior to initiation of HMV. The exclusion of patients with co-morbidities possibly contributing to anaemia (Figure 1) resulted in a study population of 595 patients aged from 21 to 84 years. OD $(n=326 ; 54.8 \%)$ comprised severe COPD $(n=304)$ and overlap syndrome $(n=22)$. RD $(n=269 ; 45.2 \%)$ comprised OHS $(n=120)$, TRD $(n=80)$, NMD $(n=48)$ and other respiratory disease $(n=21)$ (Table 1).

\section{Prevalence of anaemia in different chronic respiratory diseases}

The overall prevalence $(n=595)$ of anaemia was $13.3 \%(n=79)$, without significant difference between OD (14.7\%) and RD (11.5\%) $(\mathrm{p}=0.276)$, or between COPD $(15.1 \%)$ and RD $(11.5 \%)$ $(\mathrm{p}=0.221)$. However, the prevalence of anaemia was significantly different between TRD $(6.3 \%)$ and COPD $(15.1 \%)(\mathrm{p}=0.041), \operatorname{NMD}(20.8 \%)$ and TRD $(6.3 \%)(\mathrm{p}=0.021)$ and OD $(14.7 \%)$ and TRD $(6.3 \%)(\mathrm{p}=0.043)$. In contrast, the prevalence did not show significant differences between overlap syndrome (9.1\%), OHS (10.8\%) and other respiratory diseases (14.3\%) (Figure 2). Only in OD the prevalence of anaemia differed between females and males $(7.9 \%$ versus $17.3 \%$; $\mathrm{p}=0.035)$, whereas no such differences occurred in the total group $(\mathrm{p}=0.081)$ or in patients with $\mathrm{RD}(\mathrm{p}=1.0)$ (Figure 3).

\section{Characteristics of patients with anaemia in chronic respiratory diseases}

Patients with OD and anaemia showed higher age $(\mathrm{p}=0.003), \mathrm{pH}(\mathrm{p}=0.014)$ and arterial oxygen pressure $\left(\mathrm{PaO}_{2}\right)(\mathrm{p}=0.012)$, lower BMI $(\mathrm{p}=0.011)$ and total protein $(\mathrm{p}=0.012)$, and higher rates of male sex $(\mathrm{p}=0.035)$ coronary heart disease $(\mathrm{p}=0.01)$, cardiac arrhythmia $(\mathrm{p}=0.014)$ and diabetes mellitus $(\mathrm{p}=0.003)$ in comparison to non-anaemic patients with OD. 
Moreover, anaemic patients with OD showed less intake of theophylline $(\mathrm{p}<0.001)$. In anaemic patients with $\mathrm{RD}$, there were higher age $(\mathrm{p}=0.008), \mathrm{pH}(\mathrm{p}=0.011)$ and lower leukocyte numbers ( $\mathrm{p}=0.006)$ as compared to non-anaemic patients with RD (Table 2).

Stepwise multivariate regression analysis of all patients, including OD versus RD as binary variable, revealed that age $(\mathrm{p}=0.012), \mathrm{pH}(\mathrm{p}=0.002)$ and $\mathrm{PaO}_{2}(\mathrm{p}=0.006)$ but not the disease category were independently associated with anaemia. In OD only $\mathrm{pH}(\mathrm{p}=0.011)$ and $\mathrm{PaO}_{2}(\mathrm{p}=0.013)$ were independently associated with anaemia, while in RD leukocyte number $(\mathrm{p}=0.035)$ and $\mathrm{pH}(\mathrm{p}<0.001)$ were independent predictors of anaemia (Table 3). 


\section{DISCUSSION}

This study demonstrates that anaemia, a treatable condition, is highly prevalent in patients with CRF irrespective of the underlying disease. Anaemia was associated with age, nutritional indices and blood gas indices. In view of the heterogeneity of the study population these results suggest, that not only systemic inflammation, but also conditions associated with respiratory failure itself, contributes to the development of anaemia in respiratory diseases.

Anaemia is known to be a common feature in COPD. When defining anaemia via haemoglobin levels, prevalence rates between 13\% ( $\mathrm{Hb}<13 \mathrm{~g} / \mathrm{dl})(21)$ and $17 \%(\mathrm{Hb}<13.5 \mathrm{~g} / \mathrm{dl}$ for male, $\mathrm{Hb}<12.0 \mathrm{~g} / \mathrm{dl}$ for female) have been reported (6). In line with this our data show a prevalence of $15.1 \%$ in COPD, if anaemia was defined based on WHO criteria $(\mathrm{Hb}<12 \mathrm{~g} / \mathrm{dl}$ for females and $\mathrm{Hb}<13 \mathrm{~g} / \mathrm{dl}$ for males) (15). Remarkably, this percentage did not vary much when patients with overlap syndrome were included (14.9\%). Using the same definition for anaemia, a prevalence of $23.1 \%$ has been found in a population of 312 hospitalised COPD patients (9). In severe COPD $(n=80)$ the prevalence of anaemia (13.9\%) was similar to our results, while it was higher in less severe disease (9). Possibly, hypoxemia which often is present in more severe forms of the disease and which is known as stimulus for erythropoesis acts against the development of anaemia. This might may also explain why a lower prevalence of anaemia was found in patients with COPD who were candidates for LTOT (12.6\% in men, $8.2 \%$ in women), apart from the fact that in this study haematocrit had been used as criterion ( $<39 \%$ in men, $<36 \%$ in women) (5). As in the present investigation, the prevalence of anaemia reported in this study was also higher in males with COPD.

To the best of our knowledge, the prevalence of anaemia in patients with CRF due to other respiratory diseases than COPD has not been systematically studied so far. Our data reveal that in severe restrictive disease anaemia is nearly equally frequent, as the overall prevalence in non-COPD was $11.5 \%$ and not significantly different from that in OD or COPD. Nevertheless there were differences between diseases within this group. The highest 
prevalence was found in patients with NMD (20.8\%) and "other respiratory diseases" (14.3\%; predominantly interstitial lung disease), whereas patients with TRD showed the lowest prevalence (6.3\%). In COPD anaemia reflects prognosis (19). Correspondingly, in non-COPD patients anaemia also appears to be inversely related to long-term survival, as this is known to be best in patients with CRF due to TRD and often worse in patients with lung fibrosis or NMD such as amyotrophic lateral sclerosis. In view of this it is surprising, that also in patients with OHS anaemia was observed in a considerable number of patients.

The current study was not designed to elucidate causative mechanisms regarding anemia. Phenomenologically, anaemic patients with OD showed higher age, lower BMI and total protein, and a higher rate of relevant co-morbidities. Among these, diabetes mellitus could be causal for anaemia (20) and the development of coronary heart disease and cardiac arrhythmias probably favoured by it.

$\mathrm{ACD}$ is a frequent phenomenon in patients with acute or chronic immune activation (21). Interleukin-1, interleukin-6, tumor necrosis factor- $\alpha$ and interferon- $\gamma$ are involved in the underlying mechanism (1). These cytokines also take part in the pathogenesis of COPD (22) and therefore could contribute to the development of anaemia in $\operatorname{COPD}(5 ; 10 ; 23)$. In addition, an imbalance between the erythropoietin-stimulating effect of hypoxia and inflammationinduced erythropoietin resistance resulting in anaemia has been proposed in COPD (10). Our finding, that anaemia is present in severe respiratory disease largely irrespective of the underlying disorder suggests that inflammation probably is not the major driver of anaemia. Thus, anaemia was also prevalent in disorders such as NMD, TRD or OHS, which are commonly considered as non-inflammatory.

Among the mechanisms evoking anaemia in CRF, malnutrition probably plays a major role. Actually, haematocrit has been found to be positively correlated with BMI (5). Correspondingly, in our study patients with OD and anaemia presented with lower BMI and 
total protein. However, neither BMI nor total protein was associated with anaemia in RD. This was confirmed in an additional analysis excluding OHS patients (data not shown). Malnutrition, especially vitamin deficiency, is however also reflected in measures beyond BMI and total protein. It occurs frequently in NMD, such as duchenne muscular dystrophia (24), due to dysphagia and/or dyspnoea and needs to be treated by gastrostomy tube feeding (25). Similarly, in anorexia nervosa, anaemia is common, and weight loss is associated with the disappearance of hematopoietic cells and an increased fat fraction in bone marrow (26). This may be associated with lower leukocyte numbers, as in anaemic patients with RD in our study. Anaemia is also frequent in the elderly and often of unknown cause (27). Correspondingly, age was also associated with lower haemoglobin in the present study, in line with previous results in COPD $(5 ; 6)$. Taken together, these data suggest that anaemia in these patients is of multifactorial origin.

Dyspnoea is a known symptom in anaemia. We found a higher $\mathrm{PaO}_{2}$ and $\mathrm{pH}$, and a lower $\mathrm{PaCO}_{2}$ in anaemic patients. Among these, $\mathrm{PaO}_{2}$ and $\mathrm{pH}$ were independently associated with anaemia in OD, both of them possibly based on hyperventilation. Anaemia in COPD is linked to morbidity and mortality $(5 ; 6)$, and anaemic patients with COPD and respiratory failure might benefit from blood transfusion $(28 ; 29)$. In patients with heart failure exercise capacity improves after rising haemoglobin level (30). Thus, in addition to worsening tissue oxygenation, anaemia could increase the work of breathing and thereby contribute to the impairment of the nutritional status and prognosis in CRF.

Our study is limited by its partially retrospective design, which hampers the causative interpretation. Moreover, there might have been potential confounders of anaemia which became evident only at a later time and were not detected in our retrospective data analysis. Not only patients with stable disease were included. It appeared, however, that acute infection was not associated with a higher prevalence of anaemia. Another limitation is the lack of a control group. An age-matched control cohort is difficult to define and was not 
available in the present setting. Finally, within the spectrum of restrictive diseases the number of patients was low which affects the accuracy of the prevalence estimates in the subgroups.

In summary, this study systematically examined the prevalence of anaemia in a large cohort of patients with CRF and different types of underlying respiratory disorder. Our data indicate that anaemia is nearly as prevalent in restrictive diseases as in COPD. These results underline the assumption that in the development of severe respiratory disorder anaemia is a regular phenomenon of multifactorial origin and not only due to systemic inflammation. Practical clinicians should be aware of the high prevalence of anaemia and hence be ready to screen for nutritional deficiencies and related co-morbidities in patients with severe respiratory disease prior to the development of manifest anaemia. The clinical impact of anaemia in the different chronic respiratory diseases and effect of a correction of haemoglobin on clinical outcomes should be addressed in future prospective trials. 
F.K. participated in study design, statistical evaluation and data interpretation and wrote the manuscript. C.M. and A.T. collected the data, helped in statistical evaluation and data interpretation. R.A.J. helped in statistical evaluation of the data, their interpretation and participated in writing the manuscript. D.H. participated in study design and critical revision of the manuscript. C.P. helped in critical revision of the manuscript and data interpretation. M.P. participated in data interpretation and the initiation of the study, enabled the realization and supervised its performance. S.B. initiated the study, helped writing the manuscript and participated in statistical evaluation, study design and data interpretation. 


\section{REFERENCE LIST}

1. Weiss G, Goodnough LT. Anaemia of chronic disease. N Engl J Med 2005 Mar 10;352(10):1011-23.

2. Ezekowitz JA, McAlister FA, Armstrong PW. Anaemia is common in heart failure and is associated with poor outcomes: insights from a cohort of 12065 patients with new-onset heart failure. Circulation 2003 Jan 21;107(2):223-5.

3. Littlewood TJ. The impact of haemoglobin levels on treatment outcomes in patients with cancer. Semin Oncol 2001 Apr;28(2 Suppl 8):49-53.

4. Ma JZ, Ebben J, Xia H, Collins AJ. Hematocrit level and associated mortality in hemodialysis patients. J Am Soc Nephrol 1999 Mar;10(3):610-9.

5. Chambellan A, Chailleux E, Similowski T. Prognostic value of the hematocrit in patients with severe COPD receiving long-term oxygen therapy. Chest 2005 Sep;128(3):1201-8.

6. Cote C, Zilberberg MD, Mody SH, Dordelly LJ, Celli B. Haemoglobin level and its clinical impact in a cohort of patients with COPD. Eur Respir J 2007 May;29(5):9239.

7. Barnes PJ, Celli BR. Systemic manifestations and comorbidities of COPD. Eur Respir J 2009 May;33(5):1165-85.

8. Incalzi RA, Corsonello A, Pedone C, Battaglia S, Paglino G, Bellia V. Chronic renal failure: a neglected comorbidity of COPD. Chest 2010 Apr;137(4):831-7.

9. John M, Lange A, Hoernig S, Witt C, Anker SD. Prevalence of anaemia in chronic obstructive pulmonary disease: comparison to other chronic diseases. Int J Cardiol 2006 Aug 28;111(3):365-70.

10. Similowski T, Agusti A, MacNee W, Schonhofer B. The potential impact of anaemia of chronic disease in COPD. Eur Respir J 2006 Feb;27(2):390-6.

11. Tsantes AE, Tassiopoulos ST, Papadhimitriou SI, Bonovas S, Poulakis N, Vlachou A, et al. Theophylline treatment may adversely affect the anoxia-induced erythropoietic response without suppressing erythropoietin production. Eur J Clin Pharmacol 2003 Sep;59(5-6):379-83.

12. Weitzenblum E, Chaouat A, Kessler R, Canuet M. Overlap syndrome: obstructive sleep apnea in patients with chronic obstructive pulmonary disease. Proc Am Thorac Soc 2008 Feb 15;5(2):237-41.

13. Sleep-related breathing disorders in adults: recommendations for syndrome definition and measurement techniques in clinical research. The Report of an American Academy of Sleep Medicine Task Force. Sleep 1999 Aug 1;22(5):667-89.

14. Clase CM, Kiberd BA, Garg AX. Relationship between glomerular filtration rate and the prevalence of metabolic abnormalities: results from the Third National Health and 
Nutrition Examination Survey (NHANES III). Nephron Clin Pract 2007;105(4):c178c184.

15. Nutritional anaemias. Report of a WHO scientific group. World Health Organ Tech Rep Ser 1968;405:5-37.

16. Stevens LA, Coresh J, Greene T, Levey AS. Assessing kidney function--measured and estimated glomerular filtration rate. N Engl J Med 2006 Jun 8;354(23):2473-83.

17. Miller MR, Hankinson J, Brusasco V, Burgos F, Casaburi R, Coates A, et al. Standardisation of spirometry. Eur Respir J 2005 Aug;26(2):319-38.

18. Quanjer PH, Tammeling GJ, Cotes JE, Pedersen OF, Peslin R, Yernault JC. Lung volumes and forced ventilatory flows. Report Working Party Standardization of Lung Function Tests, European Community for Steel and Coal. Official Statement of the European Respiratory Society. Eur Respir J Suppl 1993 Mar;16:5-40.

19. Celli BR, Cote CG, Marin JM, Casanova C, Montes de OM, Mendez RA, et al. The body-mass index, airflow obstruction, dyspnoea, and exercise capacity index in chronic obstructive pulmonary disease. N Engl J Med 2004 Mar 4;350(10):1005-12.

20. Singh DK, Winocour P, Farrington K. Erythropoietic stress and anaemia in diabetes mellitus. Nat Rev Endocrinol 2009 Apr;5(4):204-10.

21. Cartwright GE. The anaemia of chronic disorders. Semin Hematol 1966 Oct;3(4):35175.

22. Barnes PJ. The cytokine network in chronic obstructive pulmonary disease. Am J Respir Cell Mol Biol 2009 Dec;41(6):631-8.

23. John M, Hoernig S, Doehner W, Okonko DD, Witt C, Anker SD. Anaemia and inflammation in COPD. Chest 2005 Mar;127(3):825-9.

24. Davidson ZE, Truby H. A review of nutrition in Duchenne muscular dystrophy. $\mathrm{J}$ Hum Nutr Diet 2009 Oct;22(5):383-93.

25. Birnkrant DJ, Ferguson RD, Martin JE, Gordon GJ. Noninvasive ventilation during gastrostomy tube placement in patients with severe duchenne muscular dystrophy: case reports and review of the literature. Pediatr Pulmonol 2006 Feb;41(2):188-93.

26. Abella E, Feliu E, Granada I, Milla F, Oriol A, Ribera JM, et al. Bone marrow changes in anorexia nervosa are correlated with the amount of weight loss and not with other clinical findings. Am J Clin Pathol 2002 Oct;118(4):582-8.

27. Guralnik JM, Eisenstaedt RS, Ferrucci L, Klein HG, Woodman RC. Prevalence of anaemia in persons 65 years and older in the United States: evidence for a high rate of unexplained anaemia. Blood 2004 Oct 15;104(8):2263-8.

28. Schonhofer B, Wenzel M, Geibel M, Kohler D. Blood transfusion and lung function in chronically anaemic patients with severe chronic obstructive pulmonary disease. Crit Care Med 1998 Nov;26(11):1824-8. 
29. Schonhofer B, Bohrer H, Kohler D. Blood transfusion facilitating difficult weaning from the ventilator. Anaesthesia 1998 Feb;53(2):181-4.

30. Mancini DM, Katz SD, Lang CC, LaManca J, Hudaihed A, Androne AS. Effect of erythropoietin on exercise capacity in patients with moderate to severe chronic heart failure. Circulation 2003 Jan 21;107(2):294-9. 
Figure 1. Selection of study population.

Definition of abbreviations: NIV=non-invasive ventilation; eGFR=estimated glomular filtration rate.

$$
168 \times 122 \mathrm{~mm}(300 \times 300 \text { DPI })
$$


Figure 2. Prevalence of anaemia in different chronic respiratory diseases $(n=595)$. The prevalence of anaemia in patients with OD $(n=326)$ was not different compared to RD $(n=269)(p=0.276)$. In patients with TRD $(n=80)$ there was a significantly lower prevalence of anaemia in comparison to OD $(n=326)(* p=0.043), \operatorname{COPD}(n=304)(* p=0.041)$ and NMD $(n=48)(* p=0.021)$.

Definition of abbreviations: $C R F=$ chronic respiratory failure; $O D=$ obstructive disease; $R D=$ restrictive diseases; $\mathrm{COPD}=$ chronic obstructive pulmonary diseases; OHS=obesitas-hypoventilation-syndrome; $\mathrm{NMR}=$ neuromuscular diseases; TRD=thoracic-restrictive diseases.

$185 \times 70 \mathrm{~mm}(300 \times 300$ DPI $)$ 
Figure 3. Prevalence of anaemia in patients with CRF $(n=595), O D(n=326)$ and RD $(n=269)$, stratified according to sex. The prevalence of anaemia was significant higher in males with OD $(n=41)$ compared to females with OD $(n=7)(* p=0.035)$.

Definition of abbreviations: $C R F=$ chronic respiratory failure; $O D=$ obstructive disease; $R D=$ restrictive diseases; $f=$ female; $m=$ male.

\section{$185 \times 67 \mathrm{~mm}(300 \times 300 \mathrm{DPI})$}




\section{TABLES}

Table 1. Patients' characteristics $(n=595)$ with either obstructive or restrictive diseases.

Variable

$\mathrm{N}$ (\% of total group)

Sex (F/M)

Age (years)

BMI $\left(\mathrm{kg} / \mathrm{m}^{2}\right)$

Previous LTOT (n/\%)

Laboratory parameters

Haemoglobin (g/dl)

Haematocrit (\%)

Leucocytes $\left(10^{3} / \mathrm{ml}\right)$

$\mathrm{CRP}(\mathrm{mg} / \mathrm{dl})$

Creatinine $(\mathrm{mg} / \mathrm{dl})$

eGFR $\left(\mathrm{ml} / \mathrm{min} / 1.73 \mathrm{~m}^{2}\right)$

Total protein $(\mathrm{g} / \mathrm{dl})$

Lung function parameters

FVC (\%predicted)

$\mathrm{FEV}_{1}$ (\%predicted)

Blood gas values without oxygen supply

$\mathrm{pH}$

$\mathrm{PaO}_{2}(\mathrm{mmHg})$

$\mathrm{PaCO}_{2}(\mathrm{mmHg})$

$\mathrm{BE}(\mathrm{mmol} / \mathrm{l})$

Co-morbidities

Chronic renal failure ${ }^{\#}(\mathrm{n} / \%)$

Coronary heart disease $(\mathrm{n} / \%)$

Left heart failure (n/\%)

Cardiac arrhythmias (n/\%)

Arterial hypertension (n/\%)

Diabetes mellitus (n/\%)

Acute infection (n/\%)
$\mathbf{N}$

Obstructive disease (OD)

$326(54.8 \%)$

$89 / 237$

326

324

$66.3(59.5 ; 71.5)$

$28.0(21.9 ; 33.6)$

$149 / 45.7$

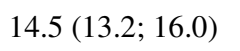

269

$44.0(40.0 ; 49.0)$

$9.3(7.5 ; 11.7)$

$7.6(4.5 ; 22.4)$

$0.9(0.8 ; 1.1)$

$87.1(69.5 ; 102.4)$

$6.6(6.1 ; 7.1)$

$52.1(44.0 ; 61.4)$

$30.8(23.1 ; 40.4)$

255

255

317

182

182

182

182

182

$\begin{array}{cc}7.42(7.39 ; 7.45) & 209 \\ 49.0(43.0 ; 55.0) & 209 \\ 53.0(48.0 ; 58.0) & 209 \\ 7.6(4.7 ; 10.2) & 209\end{array}$

7.42 (7.39; 7.45)

$52.0(46.0 ; 61.0)$

$50.0(46.0 ; 56.0)$

$6.3(4.2 ; 9.1)$

0.255

0.366

0.000

0.058

0.001

0.063

0.043

$54.1(38.0 ; 67.2)$

0.801

$50.0(35.8 ; 64.0)$

$<0.001$

47/14.4

44/16.4

$52 / 16.0$

19/7.1

$22 / 8.2$

24/8.9

$139 / 51.7$

$66 / 24.5$

$59 / 21.9$

90/27.6

48/14.7

$140 / 42.9$
0.568

0.842

$<0.001$

0.006

0.013

0.001

0.001

0.032

0.039

1.000

0.128 
Table 2. Characteristics of anaemic versus non-anaemic patients $(n=595)$.

Variable
$\mathrm{N}(\%)$
Sex $(\mathrm{F} / \mathrm{M})$
Age (years)
BMI $\left(\mathrm{kg} / \mathrm{m}^{2}\right)$
Previous LTOT (n/\%)
Laboratory parameters
Haemoglobin $(\mathrm{g} / \mathrm{dl})$
Haematocrit $(\%)$
Leucocytes $\left(10^{3} / \mathrm{ml}\right)$
CRP $(\mathrm{mg} / \mathrm{dl})$
Creatinine $(\mathrm{mg} / \mathrm{dl})$
eGFR (ml/min/1.73 m²)
Total protein $(\mathrm{g} / \mathrm{dl})$

Functional parameters

VC (\%predicted)

$\mathrm{FEV}_{1}$ (\%predicted)

Blood gas values without oxygen supply

$\mathrm{pH}$

$\mathrm{PaO} 2(\mathrm{mmHg})$

$\mathrm{PaCO} 2$ (mmHg)

$\mathrm{BE}(\mathrm{mmol} / \mathrm{l})$

\section{Co-morbidities}

Chronic renal failure ${ }^{\#}(\mathrm{n} / \%)$

Coronary heart disease $(\mathrm{n} / \%)$

Left heart failure (n/\%)

Cardiac arrhythmias (n/\%)

Arterial hypertension ( $\mathrm{n} / \%)$

Diabetes mellitus (n/\%)

Acute infection (n/\%)

\section{Medication}

Anticholinergic agents (n/\%)

$\beta_{2}$-Sympathometics ( $\left.\mathrm{n} / \%\right)$

Steroids (inhalative) $(\mathrm{n} / \%)$

Steroids (systemic) $(\mathrm{n} / \%)$

Theophylline (n/\%)

ACE-blockers (n/\%)

Angiotensin-II-blockers (n/\%)

Beta-blockers (n/\%)

Calcium-antagonists $(\mathrm{n} / \%)$

Digitalis $(\mathrm{n} / \%)$

Diuretics (n/\%)

\begin{tabular}{ccc}
\multicolumn{2}{c}{ Obstructive disease } & P value $^{\S}$ \\
Anaemic & Non-Anemic & \\
$48(14.7 \%)$ & $278(85.3 \%)$ & \\
$7 / 41$ & $82 / 196$ & 0.035 \\
$70.40(62.6 ;$ & $65.6(58.6 ; 70.8)$ & 0.003 \\
$73.9)$ & & \\
$24.4(20.9 ;$ & $28.6(22.5 ; 33.9)$ & 0.011 \\
$29.8)$ & $127 / 45.7$ & 1.000 \\
$22 / 45.8$ &
\end{tabular}

Restric
Anemic
$31(11.5 \%)$
$15 / 16$
$65.7(59.5 ;$
$71.4)$
$33.7(25.7 ;$
$43.4)$
$7 / 22.6$

$11.9(10.9$; $12.5)$

36.0 (33.3;

38.0)

$9.4(7.7 ; 11.9)$

$8.7(3.5 ; 39.7)$

$0.9(0.7 ; 1.1)$

86.2 (63.8;

117.1)

$6.4(5.8 ; 6.7)$
49.0 (36.4; $58.9)$
29.5 (22.6; 40.7)

$14.8(13.7 ; 16.2) \quad<0.001$

$45.0(42.0 ; 50.0)$

$9.3(7.5 ; 11.7)$

$7.5(4.5 ; 21.7)$

$0.9(0.8 ; 1.1)$

$87.1(69.7 ; 102.0)$

$6.6(6.2 ; 7.1)$

$53.1(45.0 ; 61.8)$

0.050

$31.0(23.8 ; 40.4)$

0.527

$<0.001$

0.873

0.851

0.780

0.975

0.012

$$
\begin{gathered}
11.5 \text { (10.8; } \\
12.0) \\
35.0(32.0 ;
\end{gathered}
$$

$37.0)$

$6.6(5.3 ; 8.4)$

$6.1(4.5 ; 33.9)$

$0.9(0.7 ; 1.0)$

88.6 (57.8;

$105.8)$

$6.3(6.0 ; 7.0)$

$55.6(41.7 ;$
$67.4)$
$51.3(42.8 ;$
$58.5)$

$53.9(37.4 ; 67.5)$

$49.2(34.3 ; 64.1)$

0.544

0.469

7.45 (7.40; $7.49)$

54.5 (46.0;

63.3)

48.5 (40.8;

56.5)

$7.2(4.2 ; 16.5)$

$10 / 20.8$

$14 / 29.2$

$6 / 12.5$

$13 / 27.1$

$21 / 43.8$

$20 / 41.7$

$17 / 35.4$

$39 / 81.3$

$45 / 93.8$

29/60.4

$31 / 64.6$

$14 / 29.2$

19/39.6

$3 / 6.3$

$6 / 12.5$

$10 / 20.8$

$11 / 22.9$

$45 / 93.8$

$\begin{array}{cc}7.41(7.38 ; 7.44) & 0.014 \\ 48.0(42.0 ; 55.0) & 0.012 \\ 53.0(48.0 ; 58.0) & 0.090 \\ 7.6(4.7 ; 10.2) & 0.951\end{array}$

$37 / 13.3$

$38 / 13.7$

$50 / 18.0$

$35 / 12.6$

$119 / 42.8$

$59 / 21.2$

$73 / 26.3$

228/82.0

250/89.9

$186 / 66.9$

$166 / 59.7$

$158 / 56.8$

$120 / 43.2$

$17 / 6.1$

21/7.6

$42 / 15.1$

$54 / 19.4$

$223 / 80.2$
7.45 (7.41; 7.46)

$57.0(49.0$;

66.8)

48.0 (39.8; 53.8)

$5.9(2.9 ; 10.6)$

0.183

0.010

0.414

0.014

1.000

0.003

0.221

0.842

0.594

0.411

0.632

$<0.001$

0.752

1.000

0.258

0.392

0.561

0.024
$9 / 29.0$

$5 / 16.1$

$3 / 9.7$

$4 / 12.9$

$21 / 67.7$

$9 / 29.0$

$10 / 32.3$
$25 / 80.6$
$7.41(7.39 ; 7.44)$

$52.0(45.5 ; 60.0)$

$50.0(46.0 ; 56.0)$

$6.4(4.3 ; 9.0)$

$35 / 14.7$

$14 / 5.9$

$19 / 8.0$

$20 / 8.4$

$118 / 49.6$

$57 / 23.9$

$49 / 20.6$

$58 / 24.4$

$84 / 35.3$

$52 / 21.8$

$43 / 18.1$

$63 / 26.5$

$105 / 44.1$

$16 / 6.7$

$41 / 17.2$

47/19.7

$33 / 13.9$

$182 / 76.5$
0.011

0.056

0.057

0.597

0.066

0.053

0.727

0.498

0.084

0.513

0.165

0.659

0.552

1.000

0.619

0.274

0.850

0.264

0.053

0.810

1.000

0.821 
Table 3. Stepwise binary logistic multivariate regression analysis for the presence of anaemia

\section{A. All patients with CRF}

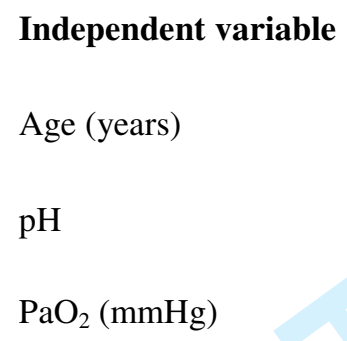

0.006

\section{B. Patients with OD}

\begin{tabular}{|c|c|c|}
\hline Independent variable & Odds ratio (95\% CI) & $P$ value \\
\hline $\mathrm{pH}$ & $<0.001(<0.001-0.041)$ & 0.011 \\
\hline $\mathrm{PaO}_{2}(\mathrm{mmHg})$ & $0.931(0.879-0.985)$ & 0.013 \\
\hline \multicolumn{3}{|l|}{ C. Patients with RD } \\
\hline Independent variable & Odds ratio $(95 \% \mathrm{CI})$ & $P$ value \\
\hline Leukocyte number $\left(10^{3} / \mu \mathrm{l}\right)$ & $1.306(1.019-1.674)$ & 0.035 \\
\hline $\mathrm{PaO}_{2}(\mathrm{mmHg})$ & $<0.001(0.001-0.098)$ & 0.020 \\
\hline
\end{tabular}

